\title{
PEMODELAN SISTEM PEMBANGKIT HYBRID ENERGI SOLAR DAN ANGIN
}

\author{
Harmini $^{1}$, Titik Nurhayati ${ }^{2)}$ \\ 1, 2) Jurusan Teknik Elektro, Fakultas Teknik Universitas Semarang, Semarang Indonesia 50196 \\ Jl. Soekarno Hatta Tlogosari, Semarang Telp (024)6702757 \\ e-mail: $\underline{\text { harmini@usm.ac.id }}{ }^{1)}$, ttknur@usm.ac.id $^{2}$
}

\begin{abstract}
Abstrak - Sistem energi hybrid adalah mengkombinasikan dua sumber energi yang akan memberikan daya ke beban. Sumber energi solar dan energi angin akan digunakan untuk menghasilkan daya. Pada penelitian ini akan dirancang sebuah model sistem hybrid pembangkit energi solar dan energi angin. Sistem yang dibuat dilengkapi dengan sistem penyimpanan energi berupa baterai. Simulasi atau pemodelan menggunakan rangkaian dengan komponen yang sesuai dengan aplikasi dilapangan. Analisa dari sistem ini adalah performansi karakteristik pembangkit hybrid berdasarkan pada perubahan beban berupa nilai tegangan, arus dan daya. Daya yang dihasilkan PLTS sebesar 3.000 Watt dan pembangkit angin sebesar 1.000 Watt dengan beban berupa beban resistif sebesar 4.000 Watt. Sistem hybrid menghasilkan daya sebesar 2.640 Watt sehingga effisiensi sistem hybrid sebesar $66 \%$
\end{abstract}

Kata Kunci: Sistem Hybrid, energi angin, energi solar

Abstract - Hybrid energy system is to combine two energy sources that will provide power to the load. Sources of solar energy and wind energy will be used to generate power. In this research will be designed a model of hybrid system of solar energy and wind energy. The system is made equipped with energy storage systems in the form of batteries. Simulation or modeling using a circuit with components appropriate to the field application. Analysis of this system is the performance of hybrid generator characteristics based on load changes in the form of voltage, current and power values. The power generated by the PLTS is 3,000 Watts and the wind generator is 1,000 Watt with a resistive load of 4,000 Watt. Hybrid system generates a power of 2640 Watt so that the efficiency of hybrid system by $66 \%$

Keywords: Hybrid system, wind energy, solar energy

\section{PENDAhuluan}

E nergi listrik merupakan kebutuhan yang sangat diperlukan dalam kehidupan sehari-hari. Ada dua jenis pembangkit energi listrik yaitu sumber energi konvensional dan non konvensional. Kebutuhan energi listrik semakin meningkat sehingga permintaan pembangkitan energi listrik juga meningkat. Saat ini, kebutuhan energi listrik dipenuhi oleh sumber energi konvensional seperti batu bara, minyak bumi, diesel, nuklir dan sebagainya. Pembangkit energi konvensional memiliki kekurangan, pembangkit energi batu bara akan menghasilkan gas $\mathrm{CO} 2$ yang berdampak pada lingkungan sedangkan energi nuklir memerlukan biaya yang tinggi, limbah energi nuklir berbahaya bagi manusia [1]. Ketersediaan energi konvensional semakin hari akan semakin habis bahkan lama kelamaan akan semakin punah,sehingga harus mencari cara lain untuk menemukan sumber energi listrik [2]. Sumber energi baru harus bisa diandalkan, bebas polusi dan ekonomis. Energi non konvensional seharusnya menjadi alternatif sumber energi bagi energi konvensional. Beberapa sumber energi non konvensional antara lain geothermal, angin, matahari, gelombang laut dan sebagainya. Energi gelombang laut

memiliki kelemahan hanya bisa diimplementasikan pada laut, sedangkan energi panas bumi memerlukan proses yang lama untuk mengambil panas dari dasar bumi. Energi matahari dan energi angin dapat disediakan pada semua kondisi, sehingga sumber energi non konvensional angin dan matahari menjadi sumber energi alternatif yang bagus untuk diterapkan. Sumber energi matahari dan angin memiliki kelemahan yaitu tidak menghasilkan energi yang besar pada musim hujan atau mendung, sehingga perlu dicari alternative atau cara untuk mengatasi hal tersebut. Salah satu cara adalah dengan menggabungkan kedua sumber energi tersebut yang biasa disebut dengan sistem hybrid. Apabila salah satu sumber energi tidak bisa menghasilkan energi maka sumber energi lain yang akan mensupplay energi ke beban [3]

Sistem energi hybrid adalah mengkombinasikan dua sumber energi yang akan memberikan daya ke beban. Dengan kata lain, sistem energi ini di rancang untuk menghasilkan daya dengan menggunakan dua sumber energi. Energi hybrid memiliki kehandalan yang tinggi, effisiensi tinggi, tidak menimbulkan polusi dan biayanya rendah [4]. Pada penelitian ini, sumber energi matahari dan energi angin akan digunakan untuk menghasilkan daya. Energi matahari dan energi angin memiliki beberapa keuntungan dibandingkan dengan sumber energi non konvensional yang lain. Keduanya tersedia disemua tempat dan tidak memerlukan tempat yang khusus untuk membangun pembangkit tersebut.

\section{SISTEM HYBRID}

\section{A. Pembangkit Listrik Tenaga Surya}

Sinar matahari yang mengenai permukaan bumi dapat dikonversikan menjadi energi listrik melalui solar sel. Solar sel terbuat dari bahan semikondukor. Solar sel memanfaatkan energi matahari untuk menghasilkan energi listrik DC (Direct Current). Energi listrik yang dihasilkan oleh solar sel tunggal sangat kecil sehingga dibutuhkan beberapa solar sel yang digabungkan menjadi sebuah panel yang disebut dengan panel surya atau panel solar photovoltaic. Pembangkit listrik yang memanfaatkan energi matahari adalah pembangkit listrik tenaga surya (PLTS). Rangkaian sel surya dapat direpresentasikan sebagai sumber arus yang terhubung paralel dengan sebuah dioda terhubung seri dengan tahanan (RS) seperti ditunjukan pada Gambar 1. 


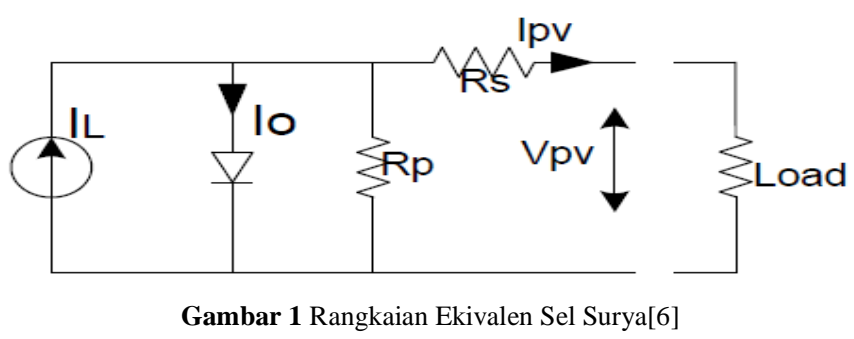

Komponen - komponen Pembangkit Listrik Tenaga Surya ditunjukkan pada Gambar 2.

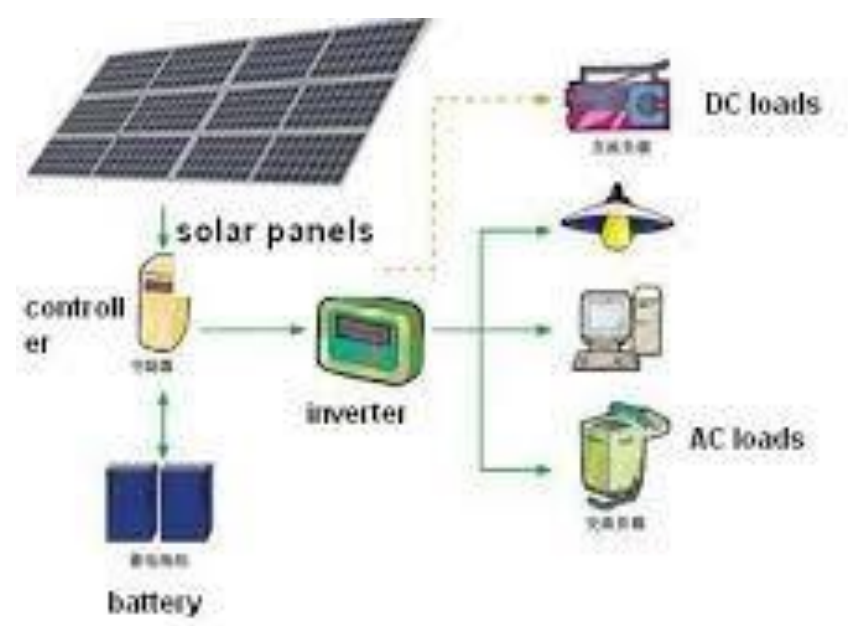

solar system for home use

Gambar 2 Komponen PLTS

\section{B. Pembangkit Listrik Tenaga Angin}

Energi angin dihasilkan dari angin dan tidak memerlukan biaya besar dalam proses pembangkitan energi listrik. Biaya pemeliharaan juga murah dan angin didapatkan dalam waktu 24 jam. Energi listrik yang dihasilkan tergantung dari kecepatan angin dan kecepatan turbin angin yang digunakan. Energi angin diubah menjadi energi listrik oleh turbin angin. Turbin angin secara umum diklasifikasikan menjadi dua yaitu axis horisontal dan axis vertical. Ekstraksi energi angin berdasarkan dari ukuran turbin angin, density, friction loss pada mesin turbin dan efisiensi konversi dari energi mekanik menjadi energi listrik. Turbin angin bekerja berdasarkan prinsip konversi energi kinetik menjadi energi mekanik untuk memutar turbin. Turbin tersebut akan dikopel oleh generator untuk diubah menjadi energi listrik[3]. Turbin angin mengubah energi kinetik yang ada angin menjadi energi mekanik dengan cara menghasilkan torsi. Energi yang terkandung angin berupa energi kinetik, maka besarnya energi yang dihasilkan tergantung pada kerapatan udara dan kecepatan angin. Daya angin yang dihasilkan ditunjukkan pada persamaan 1 .

$$
P=1 / 2 C p \rho A V^{3}
$$

Dimana $\mathrm{Cp}$ adalah coefisien daya, $\rho$ adalah density $\mathrm{Kg} / \mathrm{m} 3$, A adalah luas daerah blade turbin dalam $\mathrm{m} 2$ dan $\mathrm{V}$ adalah kecepatan angin dalam $\mathrm{m} / \mathrm{sec}$

\section{III.METODE PENELITIAN}

Penelitian ini dilaksanakan dalam kurun waktu satu semester (6 bulan) dengan membagi dalam dua tahapan yaitu tahap persiapan, tahap kedua yaitu tahap perencanaan. Lokasi penelitian adalah di Laboratorium Konversi Energi Listrik, Teknik Elektro, Fakultas Teknik sebagai tempat pengambilan data dari pembangkit listrik hybrid Pandansimo Bantul, Jogjakarta

\section{A. Model dan Rancangan Penelitian}

Model yang digunakan dalam penelitian ini adalah perancangan dan pemodelan sistem hybrid antara energi angin dan energi matahari. Proses perencanaan berdasarkan pada skema yang ditunjukkan pada Gambar 3 dan Gambar 4.

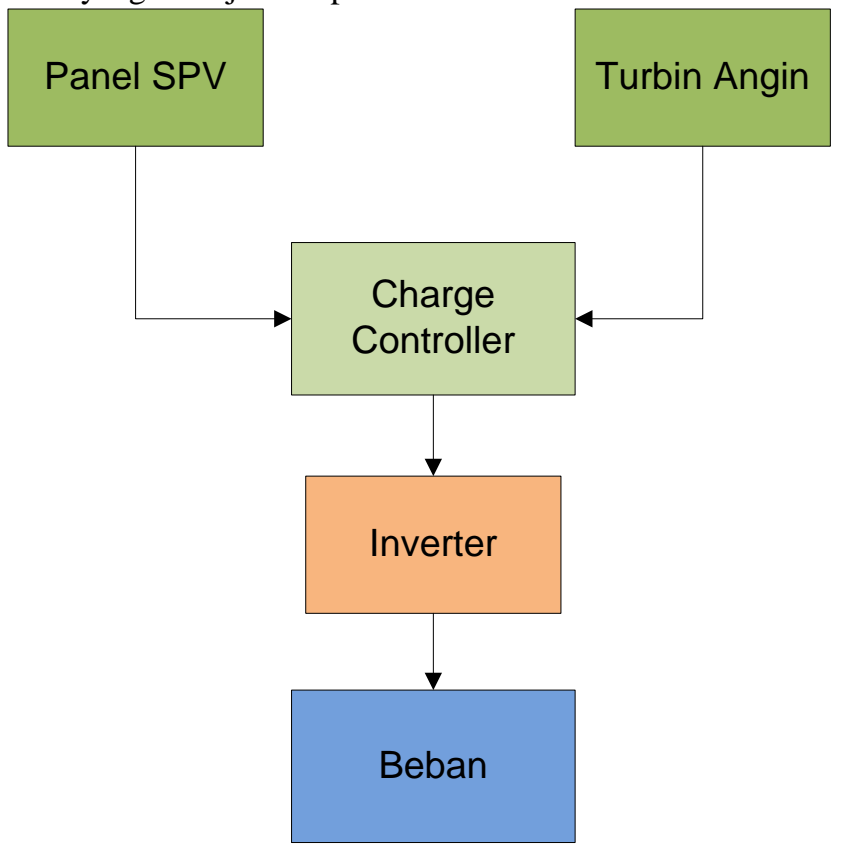

Gambar 3. Blok Diagram Sistem Hybrid 


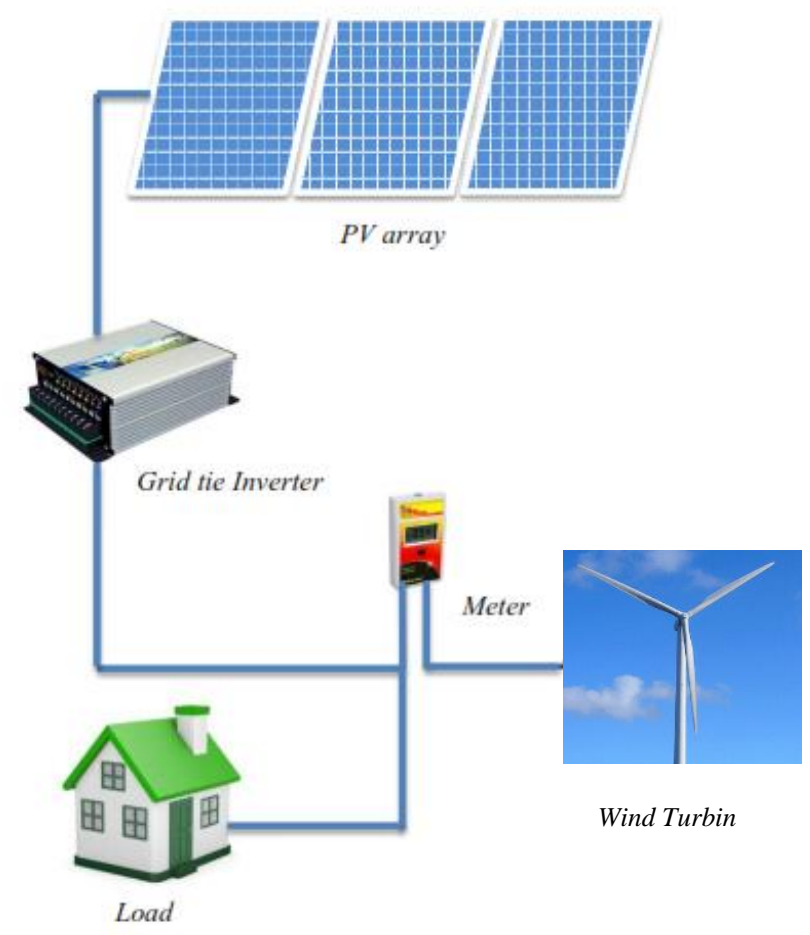

Gambar 4 Blok Diagram Sistem Hybrid

\section{HASIL DAN PEMBAHASAN}

\section{A. Rangkaian Keseluruhan Sistem Hybrid}

Hasil penelitian meliputi proses atau langkah simulasi sistem hybrid antara pembangkit listrik tenaga surya dengan pembangkit listrik tenaga angin. Gambar 5 menunjukkan gambar keseluruhan dari sistem hybrid.

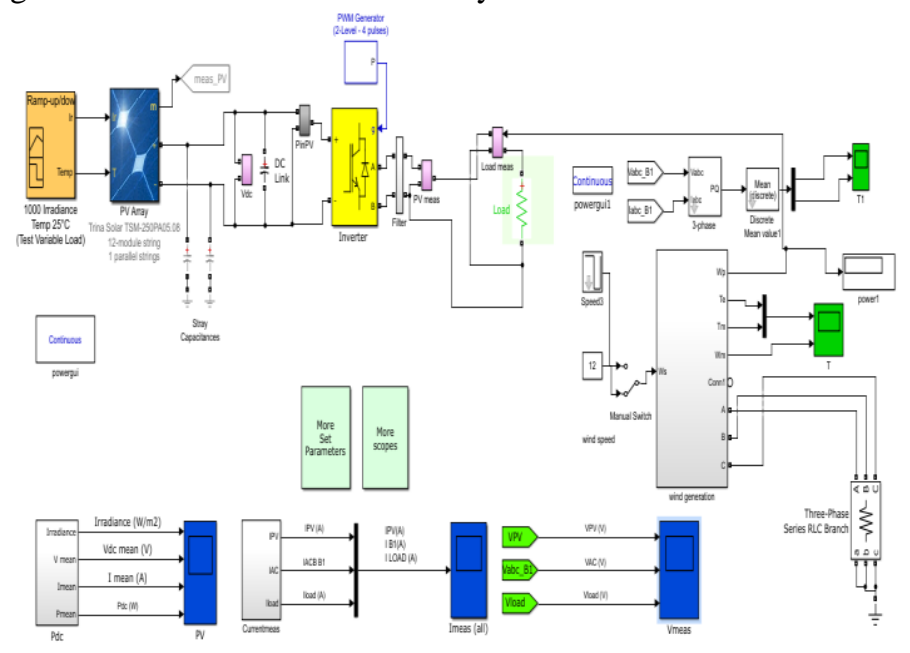

Gambar 5 Rangkaian Keseluruhan Sistem Hybrid

Kapasitas daya atau beban yang dipakai sebesar 4.000 Watt dengan asumsi 3.000 Watt dibangkitkan oleh PLTS dan 1.000 Watt dibangkitkan oleh pembangkit listrik tenaga angin

\section{B. Pembangkit Listrik Tenaga Surya}

Pembangkit listrik tenaga surya dibangun dari panel surya dan inverter. Simulasi ini tidak menggunakan baterai karena sistem yang dirancang adalah sistem on grid PV, sehingga langsung dihubungkan dengan inverter dan beban yang digunakan adalah beban AC. Jumlah panel surya yang perlukan untuk membangkitkan daya sebesar 3000 Watt sebanyak 12 buah panel. Panel surya yang digunakan adalah Trina Solar TSM -250PA05.08 dengan kapasitas daya maksimum yang dihasilkan adlaah $250 \mathrm{WP}$, sehingga jumlah panel surya yang dibutuhkan adalah:

Daya yang dibangkitkan PLTS : $3000 \mathrm{~W}$

Kapasitas modul surya $: 250 \mathrm{~W}$

Jumlah modul surya $=\frac{3000 \mathrm{~W}}{250 \mathrm{~W}}$

$$
=12
$$

Jadi jumlah modul surya yang digunakan berjumlah 12 buah dengan masing-masing modul berkapasitas $250 \mathrm{~W}$ yang dirangkai secara seri untuk menghasilkan daya output PV array sebesar 3000 W. Daya maksimum panel surya sebesar 249,86 Watt, tegangan open circuit 37.6 Volt, tengangan maksimum 31 Volt, arus short circuit sebesar 8,55 Ampere dan arus maksimum 8,05 Ampere.

\section{Pembangkit Listrik Tenaga Angin}

Simulasi pembangkit listrik tenaga angin ditunjukkan pada Gambar 6 yang terdiri dari turbin angin dan generator AC, kemudian keluaran dari generator akan dihubungkan dengan inverter (Inverter digabung menjadi satu dengan inverter pada PLTS).

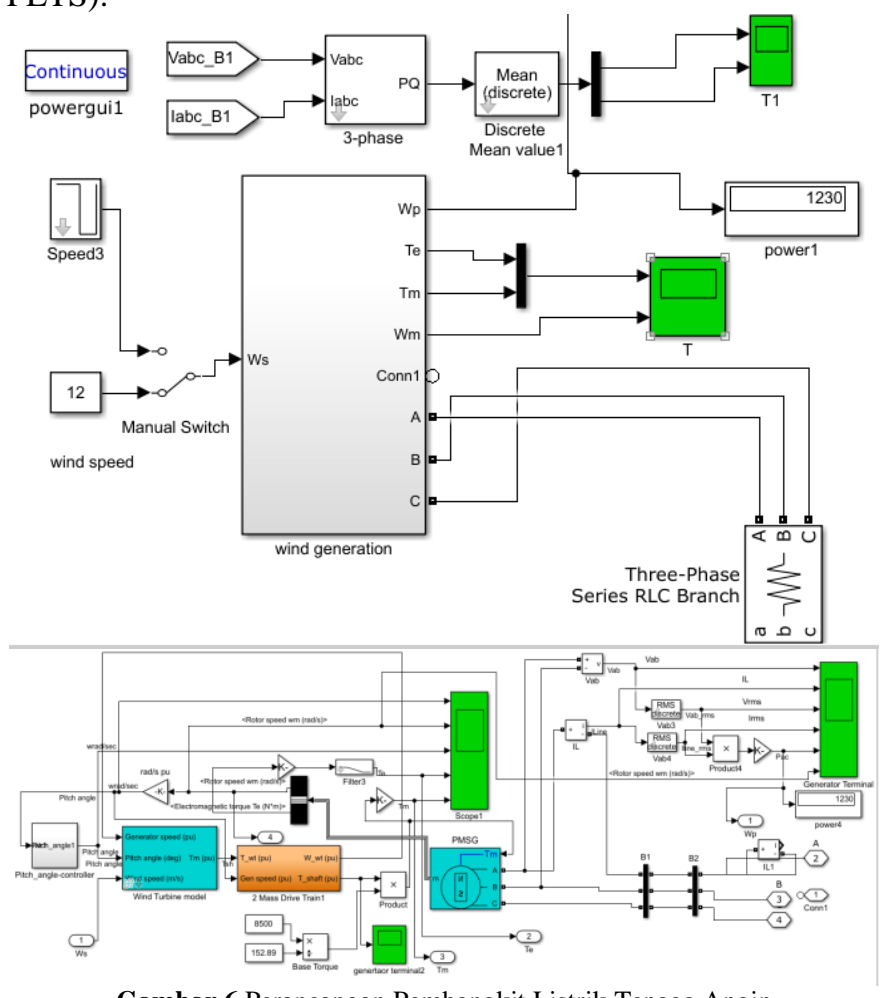

Gambar 6 Perancangan Pembangkit Listrik Tenaga Angin 
Paramater turbin ditunjukkan pada Gambar 7, dengan parameter sebagai berikut:

- Daya turbin : 1000 Watt

- Effisiensi : $90 \%$

- Kecepatan angin : $12 \mathrm{~m} / \mathrm{s}$

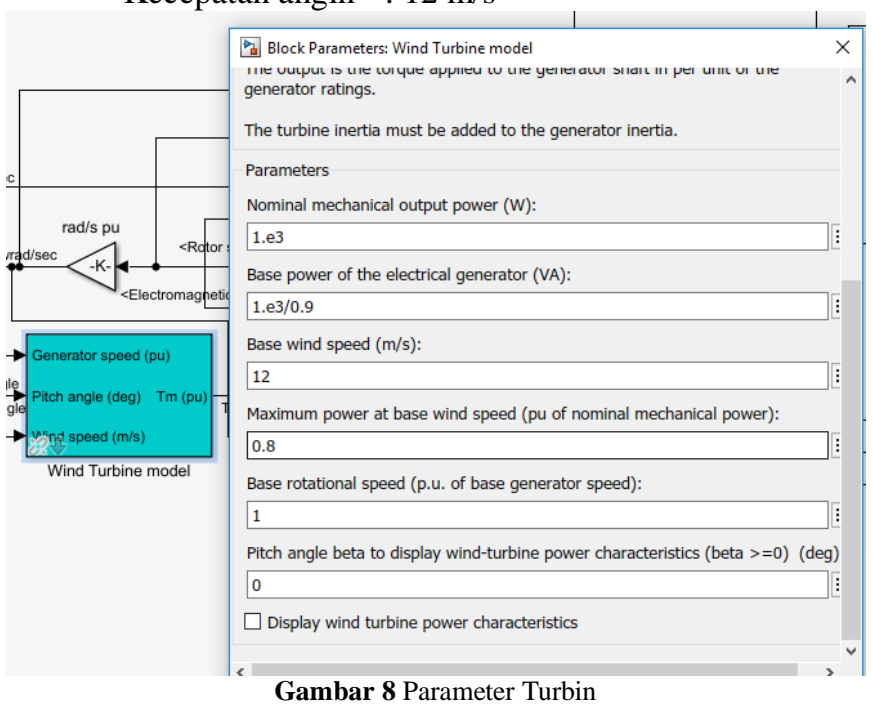

\section{Hasil Simulasi}

Gambar 9 adalah keluaran dari sistem PLTS antara lain nilai radiasi matahari sebesar $1000 \mathrm{~W} / \mathrm{m}^{2}$ dengan standart temperatur $25^{\circ} \mathrm{C}$, tegangan DC sebesar 400 Volt, Arus DC sebesar 1,4 Ampere dan daya DC sebesar 560 Watt.

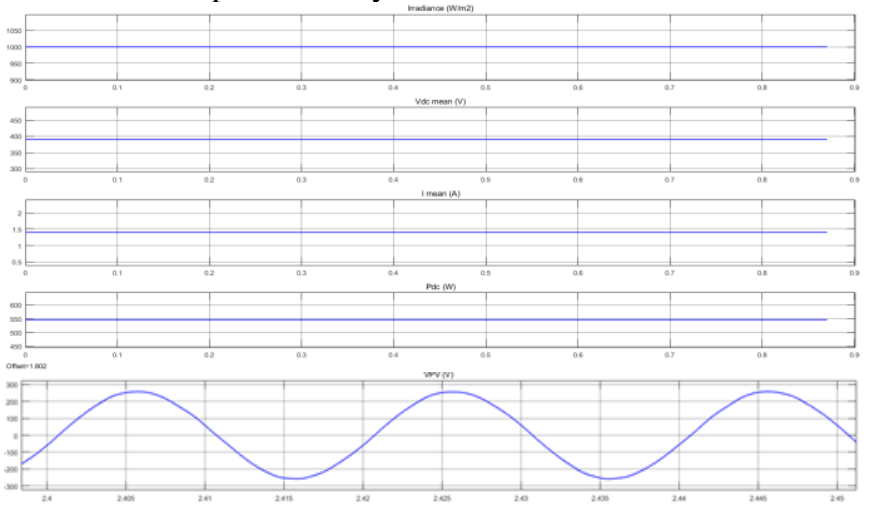

Gambar 9 Tegangan AC Keluaran Inverter PLTS

Hasil simulasi pembangkit listrik tenaga angin berupa nilai kecepatan sudut turbin, kecepatan putar rotor turbin, Torsi elektrik dan Torsi Mekanik. Gambar 10 menunjukkan hasil simulasi turbin angin, dimana kecepatan sudut turbin mengalami overshoot pada saat awal turbin mulai bekerja yaitu sebesar $1.4 \mathrm{wrad} / \mathrm{s}$ dan kecepatan sudut mulai stabil atau steady state pada saat waktu mencapai 0.1 detik sebesar $1 \mathrm{wrad} / \mathrm{s}$. Kecepatan rotor turbin juga mengalami overshoot pada saat awal turbin bekerja sebesar $200 \mathrm{rpm}$ dan mencapai kondisi steady state pada saat rotor bekerja sekitar 0.1 detik dengan kecepatan rotor sebesar $150 \mathrm{rpm}$. Torsi elektrik dan torsi mekanik turbin angin sebesar $40 \mathrm{Nm}$.

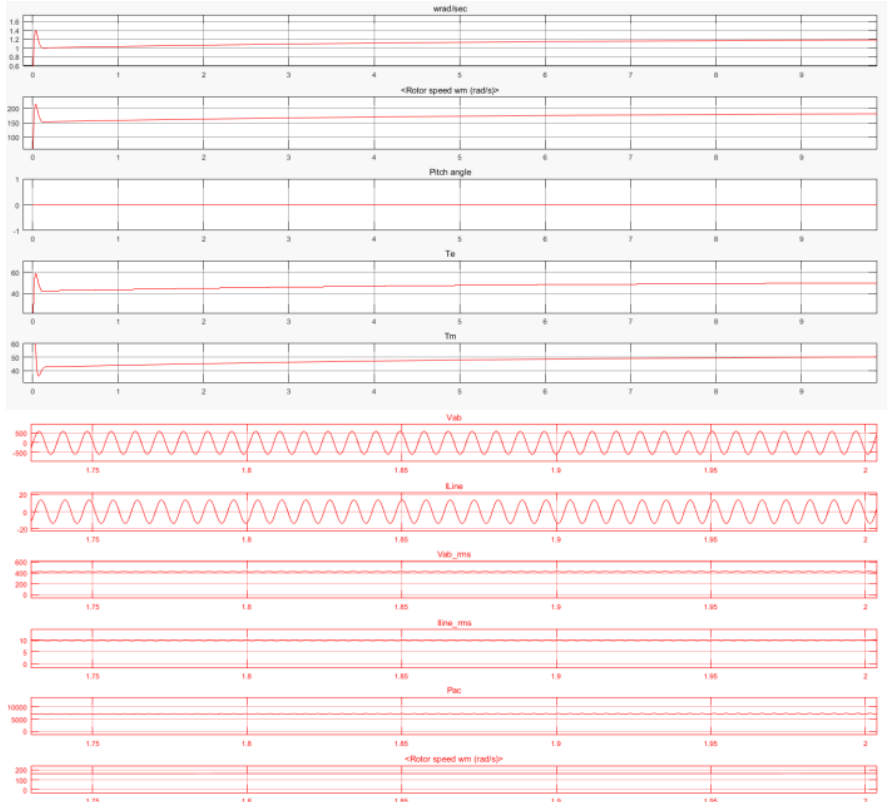

Gambar 10 Tegangan Keluaran Pembangkit Listrik Tenaga Angin

Gambar 11 menunjukkan tegangan keluaran pembangkit listrik tenaga angin, dimana generator yang digunakan adalah generator AC. Tegangan maksimum yang dihasilkan sebesar $500 \mathrm{Vac}$ dan arus maksimum sebesar 10 Ampere, sehingga daya maksimum yang dihasilkan sekitar 5000 Watt.

Sistem hybrid dibebani dengan beban daya aktif sebesar 4000 Watt. Beban ini akan di layani oleh sistem PLTS sebesar 3000 Watt dan sistem pembangkit angin sebesar 1000 Watt. Tegangan dan arus yang dihasilkan oleh sistem hybrid ditunjukkan pada gambar 11. Tegangan yang dihasilkan sistem hybrid sebesar 220 Volt dan arus kira-kira sebesar 12 Ampere, sehingga daya yang dihasilkan oleh sistem hybrid sebesar 220 $\mathrm{V}$ x $12 \mathrm{~A}=2.640$ Watt. Effisiensi sistem hybrid sebesar 2.640 Watt $/ 4.000$ watt $=0.66$ atau $66 \%$.

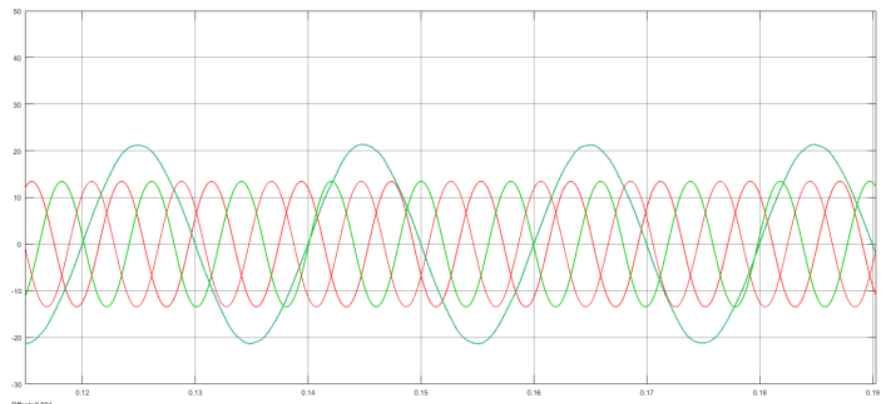

Gambar 11 Arus dan Tegangan AC keluaran sistem hybrid

\section{KESIMPULAN}

Dari penelitian yang telah dilakukan dapat diambil kesimpulan sebagai berikut:

1. Sistem hybrid dibangun dari dua buah sistem pembangkit yaitu pembangkit listrik tenaga surya (PLTS) dan 
pembangkit listrik tenaga angin. pemodelan pembangkit listrik hybrid ini menggunakan simulasi Matlab.

2. Daya yang dihasilkan PLTS sebesar 3.000 Watt dan pembangkit angin sebesar 1.000 Watt dengan beban berupa beban resistif sebesar 4.000 Watt.

3. Sistem hybrid menghasilkan daya sebesar 2.640 Watt sehingga effisiensi sistem hybrid sebesar $66 \%$.

\section{DAFTAR PUSTAKA}

[1] B.Chitti Babu and K.B.Mohanty, "Double-fed induction generator for variable speed wind energy conversion system-modelling and simulation", International journal of computer and electrical engineering, Vol.2 No.1, February, 2010, 1793-8163,pp 141-147.

[2] Deb, G, 2012,"Hybrid Power Generation System", International Journal of computer and electrical engineering, Vol.4, No.2, April 2012

[3] Geetha, U, 2015, "Design of a wind - solar hybrid power generation system in Sri Lanka"

[4] Hendrayana, 2017, "Simulasi sistem hybrid pembangkit surya, angin dan generator untuk mengoptimalkan pemanfaatan daya energi terbarukan", Jurnal Ilmiah Pendidikan Teknik Elektro, Vol.1, No.1, Februari 2017, Hal 26-43., ISSN 2549-3698.

[5] Ingole, S, Ashish, 2015,"Hybrid Power Generation System Using Wind Energy and Solar Energy", International Journal of Scientific and Research Publications, volume 5, Issue 3, March 2015, ISSN 2250-3153

[6] Kumar, S,2013,"A Hybrid Model of Solar-Wind Power Generation System", International Journal of Advanced Research in Electrical, Electronics and Instrumentation Engineering, Vol.2, Issue 8, August 2013

[7] S.A. abbasi and Naseema Abbasi,"Renewable energy source and their environment impact,"Prentice Hall of India Private Limited, 2005, pp 36.

[8] Yuliarto, B. 2011. Solar Sel Sumber Energi Terbarukan Masa Depan, www.esdm.go.id/berita/artikel/, diakses pada 18 Agustus 2017 